$06,10,11$

\title{
Методика исследования рассеяния рентгеновского излучения в монокристаллах в широком интервале температур при приложении электрического поля*
}

\author{
(C) С.А. Удовенко ${ }^{1,2}$, Д.Ю. Чернышов ${ }^{3}$, Д.А. Андроникова ${ }^{1,2}$, А.В. Филимонов ${ }^{1}$, С.Б. Вахрушев ${ }^{1,2}$ \\ ${ }^{1}$ Санкт-Петербургский политехнический университет Петра Великого, \\ Санкт-Петербург, Россия \\ ${ }^{2}$ Физико-технический институт им. А.Ф. Иофффе РАН, \\ Санкт-Петербург, Россия \\ ${ }^{3}$ Swiss_Norwegian Beam Lines at the European Synchrotron Radiation Facility, \\ Grenoble, France \\ E-mail: s_udovenko@mail.ru
}

\begin{abstract}
В статье приводится описание методики исследования рассеяния синхротронного излучения на монокристаллах в широком интервале температур с использованием разработанной нами миниатюрной конструкции для приложения электрического поля к образцу. Отличительной особенностью конструкции является возможность ее применения с различными системами нагрева и охлаждения. Разработанная методика применялась на линии BM01 в Европейском центре синхротронного излучения ESRF для изучения влияния электрического поля на процессы перестройки структуры монокристалла цирконата-титаната свинца с малой концентрацией титана. В статье демонстрируется эффективность разработанной методики и приводятся результаты предварительного анализа полученных данных.
\end{abstract}

Работа в СПбПУ Петра Великого была выполнена при поддержке гос.задания Министерства науки и образования РФ проект № 3.1150.2017/4.6. С.Б. Вахрушев благодарит за поддержку программу президиума PAH № III.2 „Физика элементарных частиц, фундаментальная ядерная физика и ядерные технологии“. Д.А. Андроникова благодарит за поддержку РФФИ (грант № 17-02-00774_a). А.В. Филимонов благодарит за поддержку РФФИ - ИНД_оми (грант № 16-52-480016).

В последние несколько лет наблюдается рост интереса к экспериментам по рассеянию синхротронного излучения, нейтронов при изменении условий, в которых находится образец. В частности, при исследовании сегнетоэлектриков, пьезоэлектриков, мультиферроиков крайне важно понимание механизмов воздействия внешнего электрического поля в широком диапазоне температур. Наиболее распространенным методом структурного анализа монокристаллов является дифракция рентгеновского (синхротронного) излучения. При проведении дифракционных экспериментов, предусматривающих воздействие на образец внешних факторов, таких как электрическое поле, ключевым моментом является создание специального устройства (ячейки), обеспечивающего заданную ориентацию образца, надежный электрический контакт между источником напряжения и образцом, а также возможность контролируемого изменения температуры образца в процессе эксперимента. На сегодняшний день существует ряд работ, в которых описаны дифракционные эксперименты при воздействии внешнего электрического поля на образец. Эксперименты, описанные в работах [1-10], проводились в относительно маленьких температурных интервалах, либо предусматривали проведение экспери-

\footnotetext{
* Доклад на XIV Международной конференции „Физика диэлектриков“" (Санкт-Петербург, 29 мая-2 июня 2017 г.).

Материалы конференции частично опубликованы в выпуске № 3 за 2018 г. журнала „Физика твердого тела“.
}

мента при комнатных температурах. Некоторые методики неприменимы для монокристаллических образцов. Поэтому нами было принято решение создать новую миниатюрную ячейку, которая бы позволила проводить измерения монокристаллов в широком температурном интервале.

Разработанная нами ячейка была протестирована при напряжениях до $10 \mathrm{kV} / \mathrm{cm}$ и температуре от комнатной до $500^{\circ} \mathrm{C}$. Конструкция ячейки позволяет проводить измерения и при низких температурах. Небольшие размеры ячейки (высота $40 \mathrm{~mm}$, ширина $15 \mathrm{~mm}$ ) позволяют использовать ее как на синхротронном источнике, так и на небольшом лабораторном дифрактометре. Изменение температуры образца в процессе эксперимента может осуществляться двумя способами: обдувом струей газа заданной температуры, либо с использованием горячего или холодного держателя.

На рис. 1 представлена фотография разработанной нами ячейки.

Электроды ячейки выполнены из меди, изолятор из лейкосапфира. Проводники представляют собой тонкие медные проволоки в термостойкой керамической изоляции.

На рис. 2 изображен монокристаллический образец, смонтированный в ячейке.

Образцы могут иметь игольчатую или пластинчатую форму длиной около $1 \mathrm{~mm}$ (вдоль направления приложения поля). 


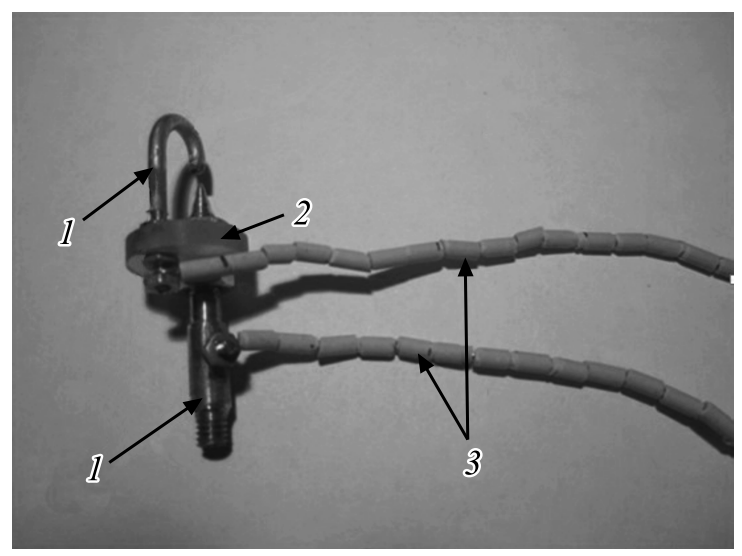

Рис. 1. Общий вид монокристальной ячейки для дифракционных экспериментов в электрических полях. Ячейка состоит из электродов -1 , изолятора -2 . Для соединения ячейки с высоковольтным источником используются гибкие проводники в термостойкой изоляции.

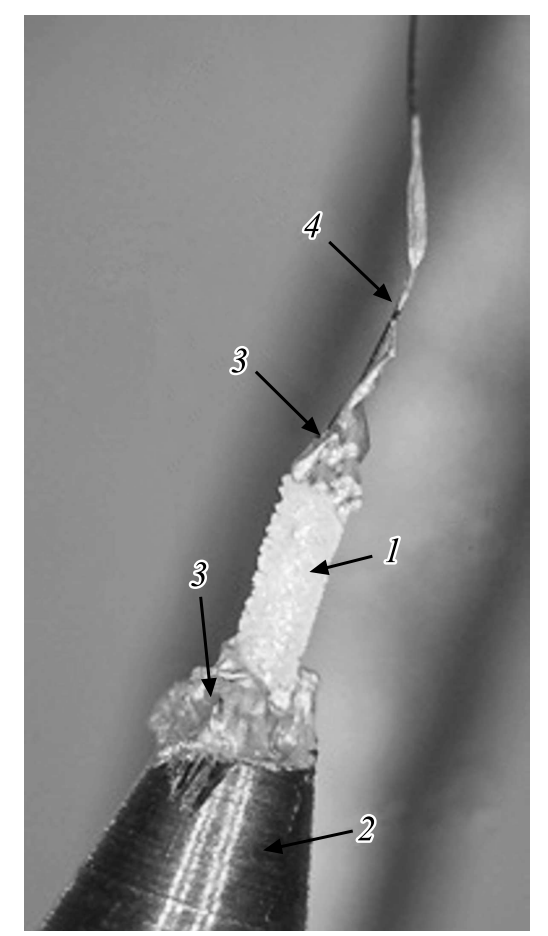

Рис. 2. Монокристаллический образец -1 приклеплен одним концом к электроду -2 , другим - к золотой проволоке толщиной $20 \mathrm{mkm}-4$, соединяющей кристалл со вторым электродом (на рисунке не показан) при помощи серебряной пасты - 3 .

Ячейка была использована для проведения предварительных исследований влияния электрического поля на диффузное рассеяние рентгеновского излучения на монокристалле $\mathrm{PbZr}_{1-x} \mathrm{Ti}_{x} \mathrm{O}_{3}$ с содержанием титана $1.5 \%$ (PZT1.5). Эксперимент был проведен в лаборатории „Швейцарско-Норвежские линии“ (SNBL) на линии ВМ01 Европейского источника синхротронного излучения ESRF (рис. 3).

Схема эксперимента приведена на рис. 4. Ячейка с образцом была закреплена на гониометре дифрактометра (GONIOMETER). Электрические выводы подключались к высоковольтному источнику постоянного напряжения (HV DC). В процессе эксперимента для поддержания необходимой температуры образца использовался обдувной нагреватель (HEAT BLOWER) Эксперимент проводился в геометрии на просвет. Пучок синхротронного излучения (BEAM) длиной волны $0.9628 \AA \AA$ после рассеяния на образце (SAMPLE) попадал в детектор (DETECTOR).

PZT1.5, как известно, претерпевает два фазовых перехода $[11]$ в диапазоне температур $30-500^{\circ} \mathrm{C}$. При охлаждении параэлектрической фазы с кубической симметрией происходит фазовый переход сначала в промежуточную фазу, симметрия которой была определена как ромбоэдрическая [12], а далее происходит переход в антисегнетоэлектрическую орторомбическую фазу [13]. Переход в антисегнетоэлектрическую фазу сопровождается возникновением на дифракционных картинах сверхструктурных отражений в узлах обратной решетки $q_{\Sigma}=(1 / 4+h 1 / 4+k l)$ (здесь и далее по тексту приняты обозначения узлов в координатах

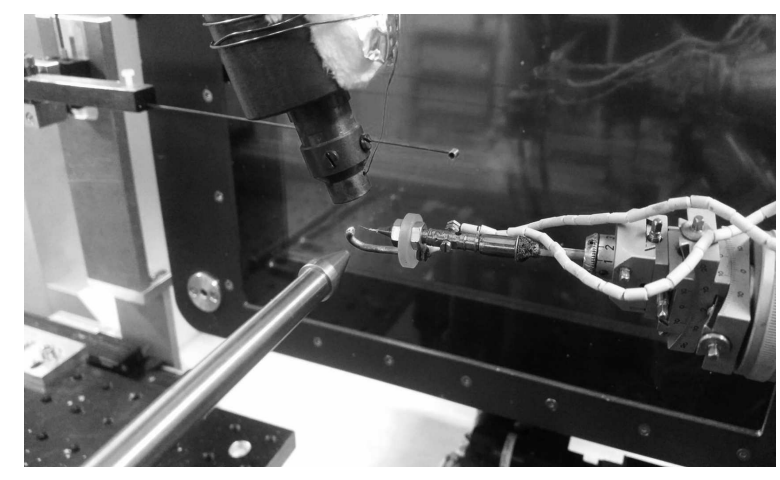

Рис. 3. Ячейка, установленная на дифрактометр Pilatus@SNBL, на линии BM01, ESRF.

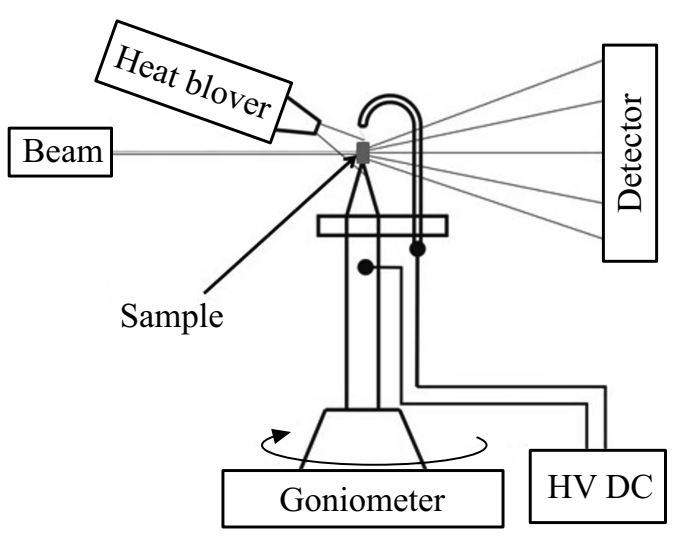

Рис. 4. Схема экспериментальной установки. 
примитивной кубической обратной решетки), называемых сверхструктурными отражениями $\Sigma$-типа, а также сверхструктурными отражениями R-типа с координатами $q_{R}=(1 / 2+h 1 / 2+k 1 / 2+l)$. Возникновение отражений $\Sigma$-типа происходит вследствие увеличения параметра элементарной ячейки в 4 раза относительно кубической, вызванного антипараллельными смещениями ионов свинца. Возникновение отражений $R$-типа связано с противофазными поворотами кислородных октаэдров, приводящих к удвоению параметров элементарной ячейки в трех направлениях. Переход в промежуточную фазу характеризуется возникновением сверхструктурных отражений $M$-типа с координатами $q_{M}=(1 / 2+h 1 / 2+k l)$. Возникновение данных сверхструктурных рефлексов может быть связано как с софазными вращениями кислородных октаэдров [14], так и с антипараллельными смещениями ионов свинца [15]. При помощи дифракции электронов было обнаружено, что в окрестности $M$-точек наблюдаются дополнительные сателлитные рефлексы, существование которых авторы объяснили наличием антифазных доменных границ в антипараллельных смещениях ионов свинца [14].

Образцы для измерений имели вид тонкой пластинки с размерами $30 \times 200 \times 1000 \mu \mathrm{m}$ с направлением длинной оси [110] в кубических координатах. В процессе измерений образец нагревался до $350^{\circ} \mathrm{C}$, затем охлаждался до $130^{\circ} \mathrm{C}$ в присутствии электрического поля $5 \mathrm{kV} / \mathrm{cm}$, при этом был обнаружен фазовый переход из кубической в сегнетоэлектрическую фазу при температуре порядка $230^{\circ} \mathrm{C}$.

Предварительная обработка полученных картин дифракции осуществлялась с применением программы SNBL toolbox [16]. Поиск матрицы ориентации осуществлялся программой CrysAlis (Oxford Diffraction Rigaku). Реконструкция обратного пространства, в результате которой было получено распределение интенсивности рассеянного синхротронного излучения в координатах обратного пространства, была произведена с использованием пакета $\pi$-тар на основе среды Matlab [17].

На рис. 5 приведены срезы обратного пространства плоскостью H0L вблизи узла (200).

При $170^{\circ} \mathrm{C}$ наблюдаются сверхструктурные отражения с координатами $\{h+1 / 4 k+1 / 4 l\}$ (сверхструктура $\Sigma$-типа), указывающие на существование антисегнетоэлектрических смещений ионов свинца. Наряду с этими отражениями по-прежнему видны отражения $M$-типа, которые можно трактовать либо как дифракцию на остатках промежуточной фазы, либо как отражения более высоких порядков по отношению к $\Sigma$-сверхструктурным отражениям $\left(2^{*} q_{\Sigma}\right)$.

Здесь впервые нами были обнаружены стержни диффузного рассеяния вокруг сверхструктурных отражений (см. рис. 5,a). Для большей наглядности был реконструирован небольшой объем обратного пространства вокруг узла 00-2 при температуре $170^{\circ} \mathrm{C}$ (рис. 6).
На рис. 6 приведено пространственное распределение диффузного рассеяния в виде стержня, которое может быть связано с рассеянием на антифазных доменных
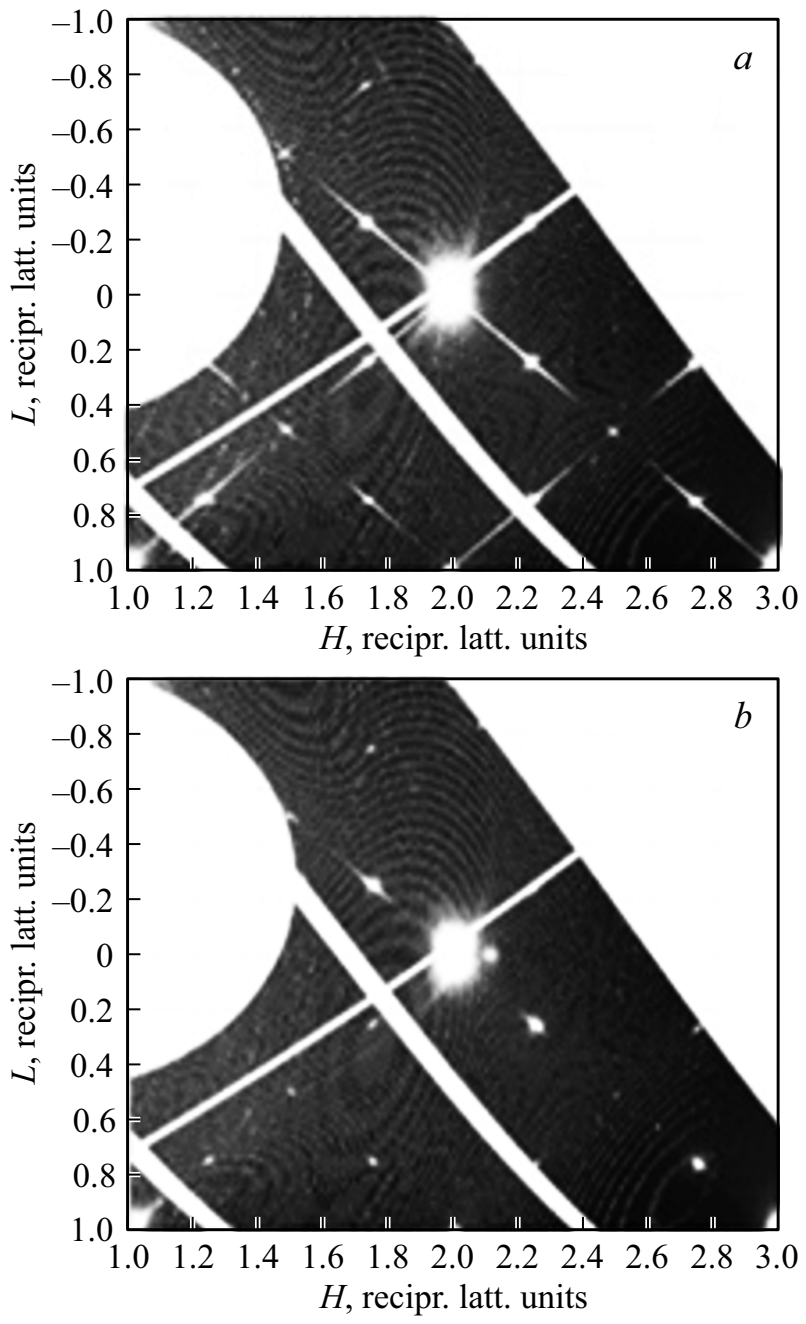

Рис. 5. Срез обратного пространства плоскостью H0L вблизи узла (200): a) $0 \mathrm{kV} / \mathrm{cm}, b) 5 \mathrm{kV} / \mathrm{cm}$ при температуре $170^{\circ} \mathrm{C}$.

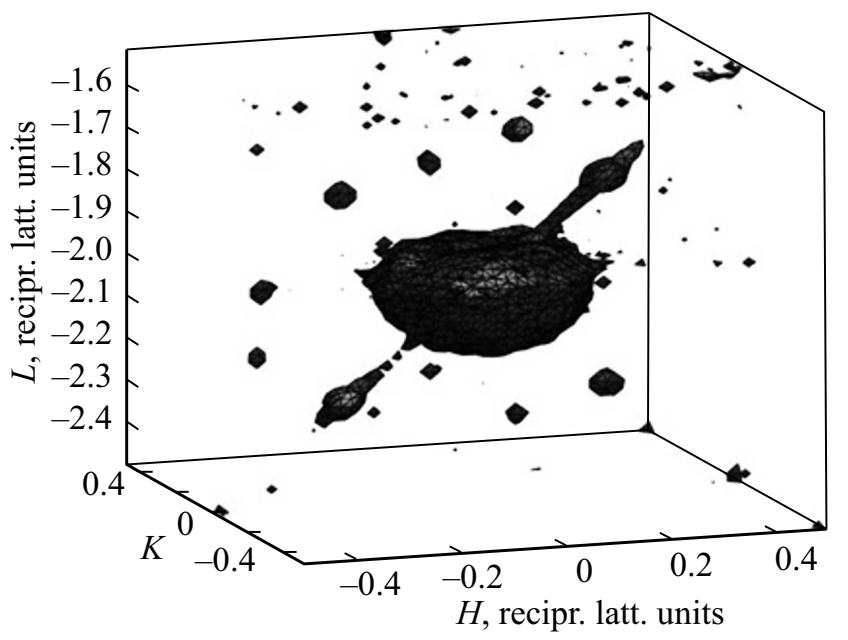

Рис. 6. Реконструированный объем обратного пространства вокруг узла $00-2, T=170^{\circ} \mathrm{C}$. 


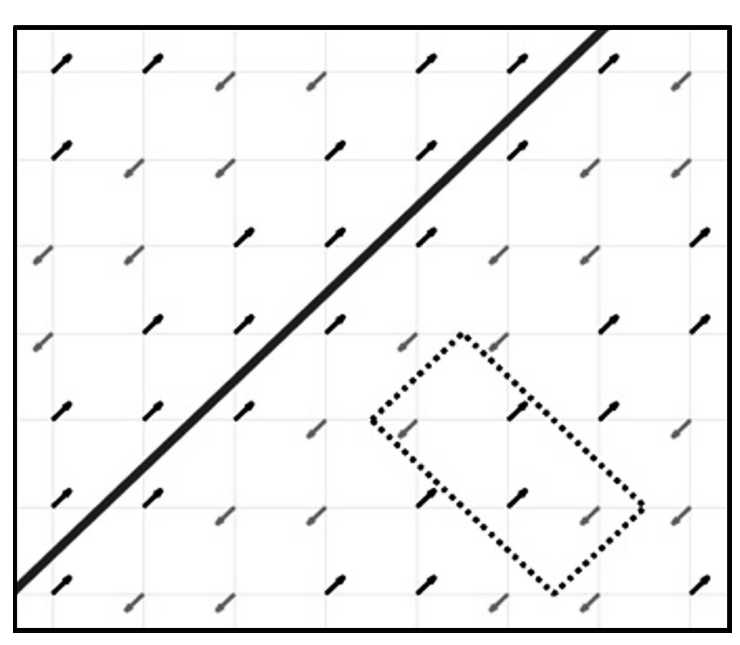

Рис. 7. Схематическое изображение антифазной доменной границы, стрелками указаны направления смещений ионов свинца, пунктирная линия - элементарная ячейка, антисегнетоэлектрической фазы, сплошной линией обозначена антифазная доменная граница.

стенках. Вопрос о сегнетоэлектрических антифазных доменных стенках подробно рассмотрен в работе [18]. Было показано, что возникновение таких стенок есть результат нарушения трансляционной симметрии на $a_{c}$, $2 a_{c}$, или $3 a_{c}$, где $a_{c}$ - параметр неискаженной решетки в кубической фазе. На рис. 7 изображены антисегнетоэлектрические смещения ионов свинца, формирующие антифазные доменные стенки.

Проведенные измерения выявили, что приложение поля существенно влияет на следующие детали картины рассеяния.

1. При охлаждении образца в электрическом поле отражения $\Sigma$-типа в направлении [110] (перпендикулярно направлению поля) появляются при более низких температурах, чем при отсутствии электрического поля.

2. При переходе кристалла из кубической фазы в низкосимметричную в поле $5 \mathrm{kV} / \mathrm{cm}$ стержнеобразное диффузное рассеяние в направлении [1110] оказывается подавленным (рис. $5, b$ ), что указывает на влияние электрического поля на доменную структуру антисегнетоэлектрической фазы.

Таким образом, нами была создана ячейка для проведения рентгеновских исследований монокристаллов при высоких температурах и в электрических полях до $10 \mathrm{kV} / \mathrm{cm}$ и продемонстрирована ее работоспособность. Ячейка может быть использована как для дифракционных измерений, так и для изучения неупругого рассеяния. Конструкция ячейки обеспечивает широкий диапазон углов $0-300^{\circ}$, что позволяет нам исследовать большой объем обратного пространства. Получены первые результаты изучения влияния электрического поля на картину рассеяния рентгеновского излучения на образце PZT1.5.

\section{Список литературы}

[1] С.Б. Вахрушев, А.А. Набережнов, Н.М. Окунева. ФТТ 40, 10, 1905 (1998).

[2] P.M. Gehring, K. Ohwada, G. Shirane. Phys. Rev. B 70, 014110 (2004).

[3] Guangyong Xu, P.M. Gehring, G. Shirane. Phys. Rev. B 72, 214106 (2005).

[4] G. Xu, Z. Zhong, Y. Bing, Z.-G. Ye, G. Shirane. Nature. Mater. 5, 134 (2006).

[5] C. Stock, G. Xu, P.M. Gehring, H. Luo, X. Zhao, H. Cao, J.F. Li, D. Viehland, G. Shirane. Phys. Rev. B 76, 064122 (2007).

[6] Kristin A. Schünau. Phys. Rev. B 76, 144112 (2007).

[7] J. Leist, H. Gibhardt, K. Hradil, G. Eckold. J. Phys.: Condens. Matter. 20, 415209 (2008).

[8] E. Daniels, A. Pramanick, J.L. Jones. IEEE Trans. Ultrason Ferroelectr. Freq. Control. 56, 8, 1539 (2009).

[9] A. Iida, I. Nishiyama, Y. Takanishi. Phys. Rev. E 89, 032503 (2014).

[10] T.Yu. Vergentev, V. Dyadkin, D.Yu. Chernyshov. J. Surf. Investigation, 9, 3, 436 (2015).

[11] V.V. Eremkin, V.G. Smotrakov, E.G. Fesenko. Solid State Phys., 31, 6, 1 (1989).

[12] V.J. Tennery. J. Am. Ceram. Soc. 49, 483 (1966).

[13] F. Jona, G. Shirane, F. Mazzi, R. Pepinsky. Phys. Rev. 105, 849 (1957).

[14] Z. Xu, X. Dai, J.-F. Li, D. Viehland. Appl. Phys. Lett. 66, 22, 2963 (1995).

[15] J. Ricote, D.L. Corker, R.W. Whatmore, S.A. Impey, A.M. Glazer, J. Dec, K. Roleder. J. Phys.: Condens. Matter. 10, 8, 1767 (1998).

[16] V. Dyadkin, P. Pattison, V. Dmitriev, D. Chernyshov. J. Synchrotron Rad. 23, 825 (2016).

[17] Ю.А. Бронвальд. Св-во о гос. регистрации программы для ЭВМ № 2017617111.

[18] X.-K. Wei, A.K. Tagantsev, A. Kvasov, K. Roleder, ChunLin Jia, N. Setter. Nature Commun. 5, 1 (2014). 